\title{
Comparison between Fuzzy Logic and PI Control for the Speed of BLDC Motor
}

\author{
Akram H. Ahmed, Abd El Samie B. Kotb, Ayman M.Ali \\ Department of Electrical Engineering, Al-Azhar University, Cairo, Egypt
}

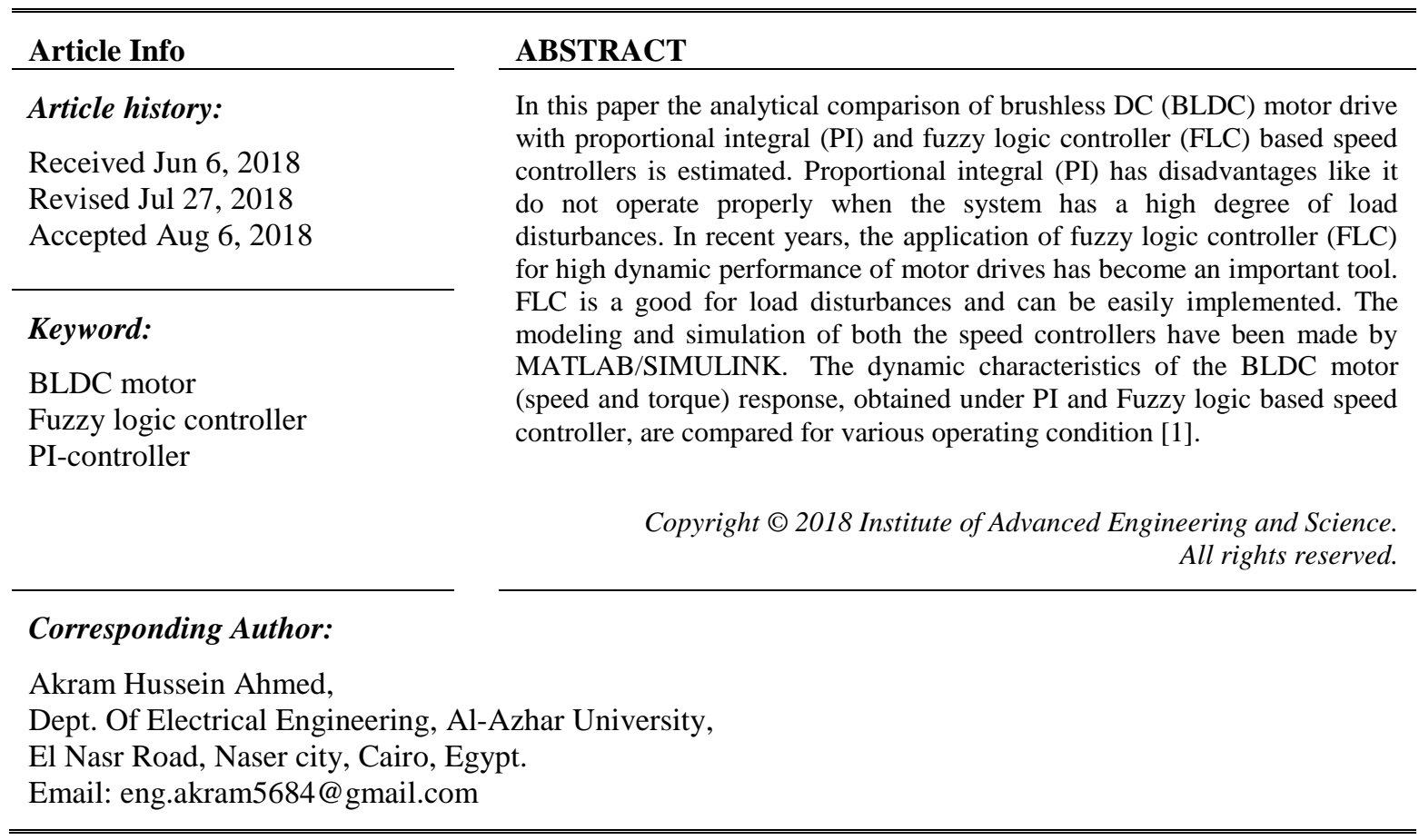

\section{INTRODUCTION}

BLDC motor is defined as a type of self-synchronous rotary motor controlled by electronic commutation unlike DC motors have mechanical commutator. So BLDC motors do not have brushes but DC motors used to have brushes. Due to BLDC motors do not have brushes its life time can be increased and maintenance operation can avoid. BLDC motors have advantages better than DC motors and Induction motors such as better speed-torque characteristics, high efficiency, high dynamic response and wide speed ranges [1]. The proportion integral (PI) controller is used for amplify the speed error and adjust gate pulse signal to control the six switches of the three phase bridge [2]. A PI controller is the most common controller in speed closed loop system which is widely used in the industries due to its capabilities in controlling linear plants [4]. However, it has problem in controlling nonlinear plants such as electrical machines. These machines might behave as a nonlinear system, where non-linearity may appear due to armature current limitations, change of load and drive inertia [5], [6]. Thus, an artificial intelligent controller such as fuzzy controller is needed to improve the speed response. It reduces the transient at the starting point and make it constant in short time of period [3]. A comparison is done between the PI speed controller and Fuzzy Logic speed controller to know which gives the better results.

In this paper, PI controller is the most common controller in speed loop feedback system which is widely used in the industries due to its capabilities in controlling linear plants. However, it faces problem in controlling nonlinear plants such as electrical machines. The step response of the drive system for a given reference speed is one of the performance indicator of the speed controller. It is desired that the step response of the system can achieve fast settling response and without overshoot. However, PI controller cannot be tuned in such a way that the optimum step response is achieved for different inertia, load and speed reference [7]. Thus, an intelligent controller such as fuzzy controller is needed for improving the speed response [8], [9]. It may reduce the transient at the starting point and make it constant in short time of period. Therefore, 
the system would be more efficient to control the speed of BLDC motor. In general, fuzzy logic controller incorporates human intelligence into the process control application which can give better dynamic response of the system [10]. At future work we can use neural network or genetic algorithm to improve the speed response. A comparison is done between the PI speed controller and Fuzzy Logic speed controller to know which gives the better results.

\section{RESEARCH METHOD}

Typically, the mathematical model of a brushless DC motor is not totally different from the conventional DC motor. The major difference is the phases involved in the operation of BLDC motor drive will peculiarly affect the resistive and the inductive nature of the BLDC model arrangement [2]. The equivalent circuit of BLDC motors shown in Fig.1.The dynamic equations of BLDC motor can be expressed in this matrix form :

$$
\left[\begin{array}{l}
\mathrm{u}_{\mathrm{A}} \\
\mathrm{u}_{\mathrm{B}} \\
\mathrm{u}_{\mathrm{C}}
\end{array}\right]=\left[\begin{array}{lll}
\mathrm{R} & 0 & 0 \\
0 & \mathrm{R} & 0 \\
0 & 0 & \mathrm{R}
\end{array}\right]\left[\begin{array}{c}
\mathrm{i}_{\mathrm{A}} \\
\mathrm{i}_{\mathrm{B}} \\
\mathrm{i}_{\mathrm{C}}
\end{array}\right]+\left[\begin{array}{ccc}
\mathrm{L}-\mathrm{M} & 0 & 0 \\
0 & \mathrm{~L}-\mathrm{M} & 0 \\
0 & 0 & \mathrm{~L}-\mathrm{M}
\end{array}\right] \frac{\mathrm{d}}{\mathrm{dt}}\left[\begin{array}{c}
\mathrm{i}_{\mathrm{A}} \\
\mathrm{i}_{\mathrm{B}} \\
\mathrm{i}_{\mathrm{C}}
\end{array}\right]+\left[\begin{array}{c}
\mathrm{e}_{\mathrm{A}} \\
\mathrm{e}_{\mathrm{B}} \\
\mathrm{e}_{\mathrm{C}}
\end{array}\right]
$$

The electromagnetic torque developed by the motor is given by

$$
\mathrm{T}_{\mathrm{e}}=\frac{\mathrm{e}_{\mathrm{A}} \mathrm{i}_{\mathrm{A}}+\mathrm{e}_{\mathrm{B}} \mathrm{i}_{\mathrm{B}}+\mathrm{e}_{\mathrm{C}} \mathrm{i}_{\mathrm{C}}}{\Omega}
$$

The motion equation has to be included as

$$
\mathrm{T}_{\mathrm{e}}-\mathrm{T}_{\mathrm{L}}=\mathrm{J} \frac{\mathrm{d} \Omega}{\mathrm{dt}}+\mathrm{B}_{\mathrm{v}} \Omega
$$

Where

$\begin{array}{clll}\mathrm{u}_{\mathrm{A}}, \mathrm{u}_{\mathrm{B}}, \mathrm{u}_{\mathrm{C}} & \text { are phase voltage }(\mathrm{V}) & \mathrm{Te} & \text { is electromagnetic torque }(\mathrm{N} . \mathrm{m}) \\ \mathrm{i}_{\mathrm{A}}, \mathrm{i}_{\mathrm{B}}, \mathrm{i}_{\mathrm{C}} & \text { are phase current }(\mathrm{A}) & \mathrm{TL} & \text { is load torque }(\mathrm{N} . \mathrm{m}) \\ \mathrm{e}_{\mathrm{A}}, \mathrm{e}_{\mathrm{B}}, \mathrm{e}_{\mathrm{C}} & \begin{array}{l}\text { are phase back e.m.f }(\mathrm{V}) \\ \mathrm{R}\end{array} & \Omega & \text { is angular velocity }(\mathrm{rad} / \mathrm{s}) \\ & \text { is phase resistance }(\mathrm{ohm}) & \mathrm{B} & \text { is damping constant }(\mathrm{N} . \mathrm{s} / \mathrm{m}) \\ \mathrm{L} & \text { is self inductance }(\mathrm{H}) & \mathrm{J} & \text { is moment of inertia }\left(\mathrm{kg} . \mathrm{m}^{2}\right) \\ \mathrm{M} & \text { is mutual inductance }(\mathrm{H}) & \Omega \mathrm{r} & \text { is refrence angular velocity }(\mathrm{rad} / \mathrm{s})\end{array}$

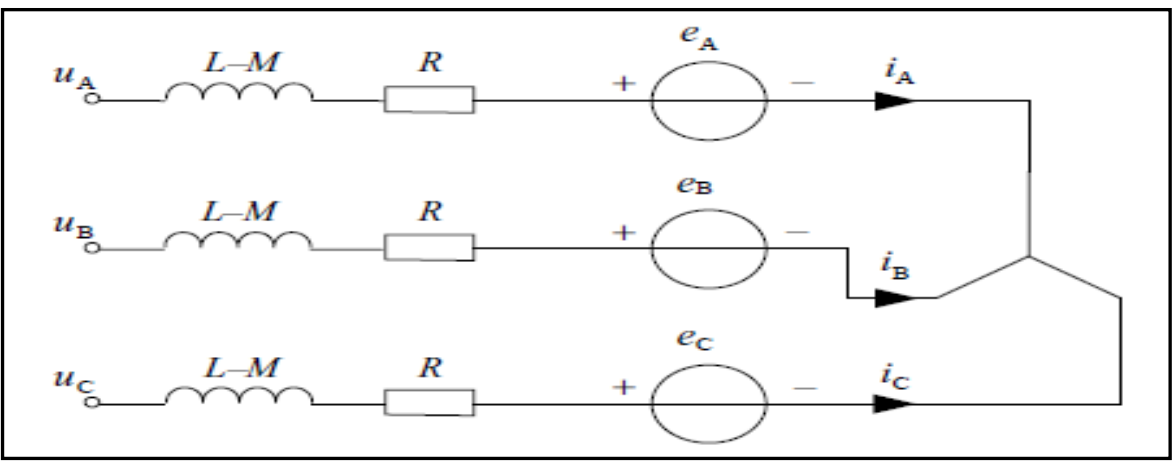

Figure 1. Equivalent circuit of BLDC motor

The transfer function of BLDC motor is expressed by

$$
\begin{aligned}
& G_{u}(s)=\frac{\Omega(s)}{U_{d}(s)}=\frac{K_{T}}{L_{a} J S^{2}+\left(r_{a} J+L_{a} B_{v}\right) S+\left(r_{a} B_{v}+K_{e} K_{t}\right)} \\
& G_{L}(S)=\frac{\Omega(S)}{T_{L}(S)}=-\frac{r_{a}+L_{a} S}{L_{a} J S^{2}+\left(r_{a} J+L_{a} B_{v}\right) S+\left(r_{a} B_{v}+K_{e} K_{T}\right)}
\end{aligned}
$$


Where

$\mathrm{K}_{\mathrm{e}} \quad$ coefficient of line back-EMF

$\mathrm{K}_{\mathrm{T}} \quad$ the torque coefficient

\section{CONTROLLERS}

A comparative study of speed control of Brushless DC (BLDC) motor drive with ProportionalIntegral (PI) and Fuzzy Logic (FL) based speed controllers is evaluated.

\subsection{PI Speed Controller}

The actual speed of BLDC motor is obtained by using the speed position encoder. The actual speed of the motor compared with reference speed and the resulting error is estimated as

$$
\Omega_{e}=\Omega_{r}-\Omega_{r}^{*}
$$

The resulting error is given to PI controller. The transfer function of of PI controller is estimated as

$$
\mathrm{Gs}(\mathrm{S})=\mathrm{K}_{\mathrm{P}}\left(1+1 / \mathrm{T}_{\mathrm{i}} \mathrm{S}\right)
$$

Where $T_{i}=K_{P} / K_{i}$ known as integral time constant and $K_{P}, K_{i}$ the proportional, integral gain respectively [4], [6]. The simulink model of BLDC motor is shown in Figure 2 and The PI speed controller as shown in Figure 3.

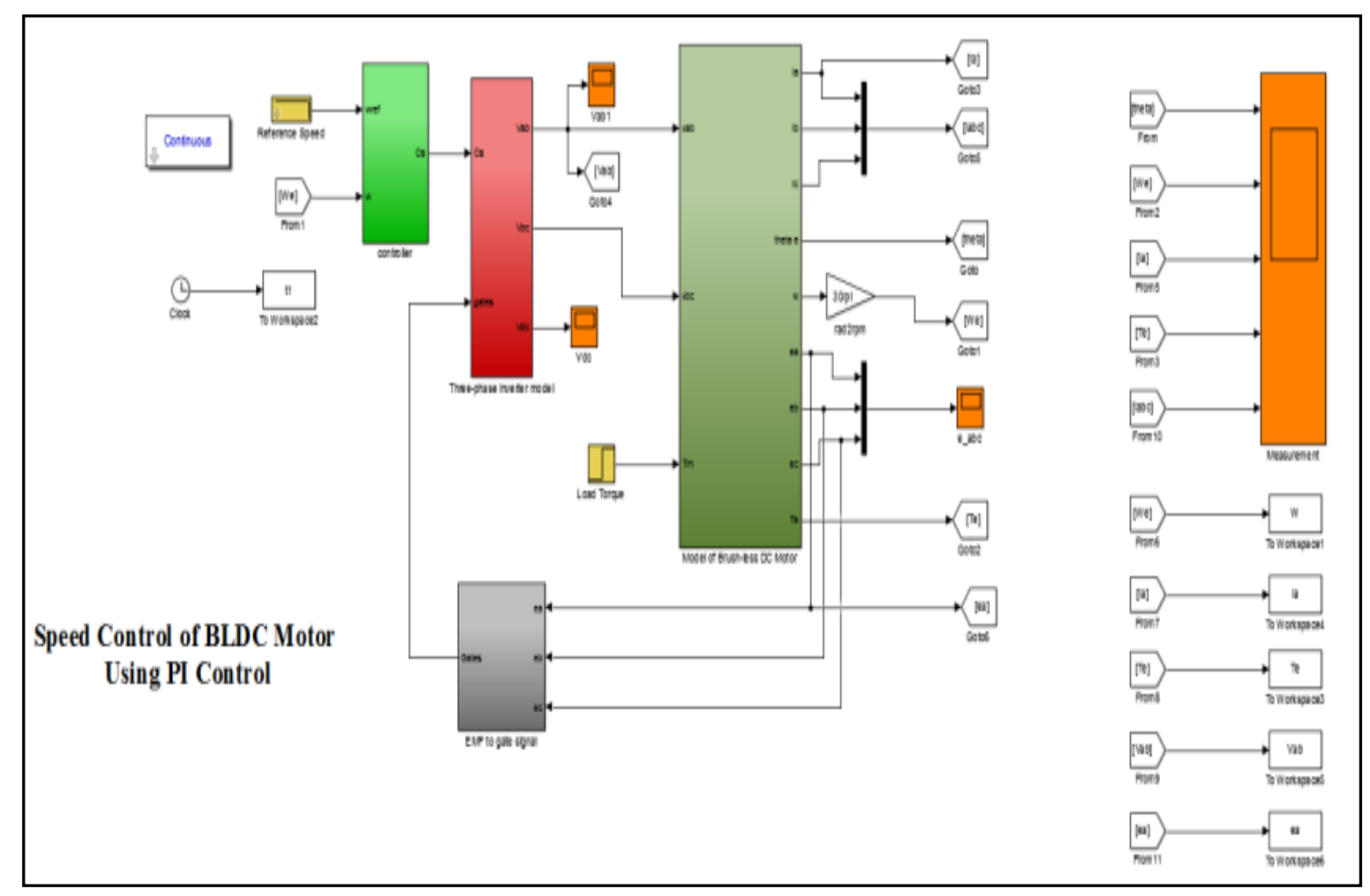

Figure 2. Simulink Model of BLDC Motor Speed Control Using PI Control 


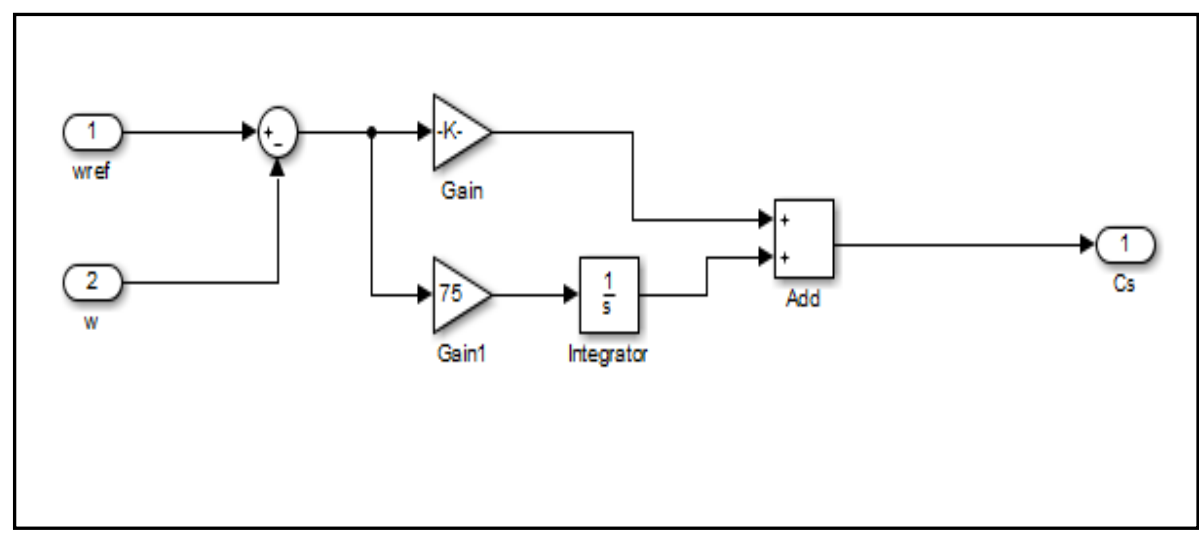

Figure 3. PI Controller Block

\subsection{Fuzzy Logic Control}

As shown in Figure 3, a typical fuzzy-control system is composed of a fuzzy controller and a plant. The fuzzy controller involves four components: fuzzification, knowledge database (including the database and rule base), fuzzy inference and defuzzification. Fundamentally, fuzzy control can reflect human reasoning. It is an intelligent control method that is independent of the precise mathematical model of the controlled object. Whether the controlled object is linear or nonlinear, a fuzzy controller can be implemented effectively with good robustness and adaptability [8].

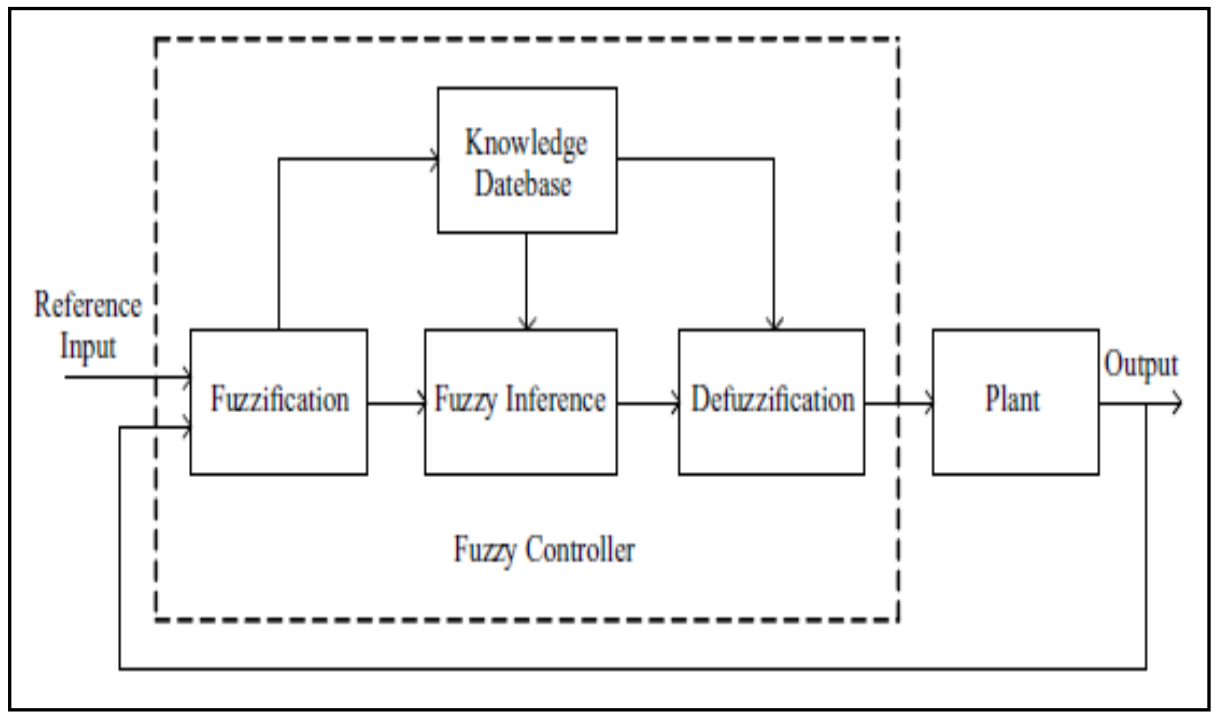

Figure4. Typical Diagram of a Fuzzy-control System

\subsubsection{Fuzzy Inference System}

Fuzzy logic has rapidly become one of the most successful of today's technology for developing sophisticated control system. It is a rule based controller. The most important things in fuzzy logic control system designs are the process design of membership functions for input, outputs and the process design of fuzzy if-then rule knowledge base [8]. Fuzzy Inference system for BLDC motor has one input (rotor position angle- theta) and three outputs (phase A, phase B, phase C) as shown in Figure 5, Input have six membership function which ranges from -180 to+180 (representing the angle) shown in Figure 6 and outputs have three membership functions $-1,0,+1$ (representing ON and OFF) shown in Figure 7. The Fuzzy logic controller shown in Figure 8 and the simulink model of BLDC motor with fuzzy logic controller is shown in Figure 9 Fuzzy rules are made according to the Table 1 [8], [9]. 


\begin{tabular}{cccc}
\multicolumn{4}{c}{ Table 1. Fuzzy Rules } \\
\hline $\begin{array}{c}\text { Rotor Position angle } \\
\text { theta) }\end{array}$ & Phase A & Phase B & Phase C \\
\hline$-180 \rightarrow-120$ & -1 & 0 & 1 \\
$-120 \rightarrow-60$ & 0 & -1 & 1 \\
$-60 \rightarrow 0$ & 1 & -1 & 0 \\
$0 \rightarrow 60$ & 1 & 0 & -1 \\
$60 \rightarrow 120$ & 0 & 1 & -1 \\
$120 \rightarrow 180$ & -1 & 1 & 0 \\
\hline
\end{tabular}

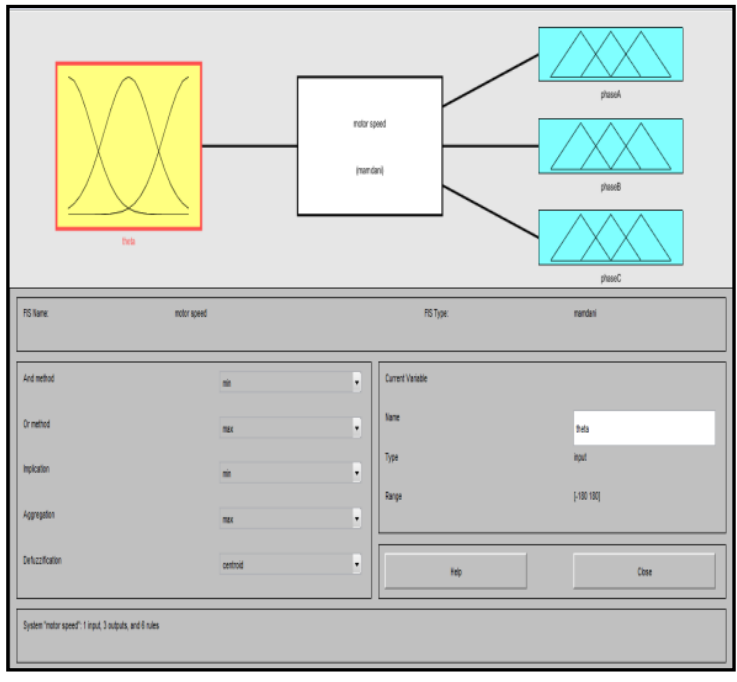

Figure 5. Fuzzy Inference System for BLDC Motor Speed Controlling

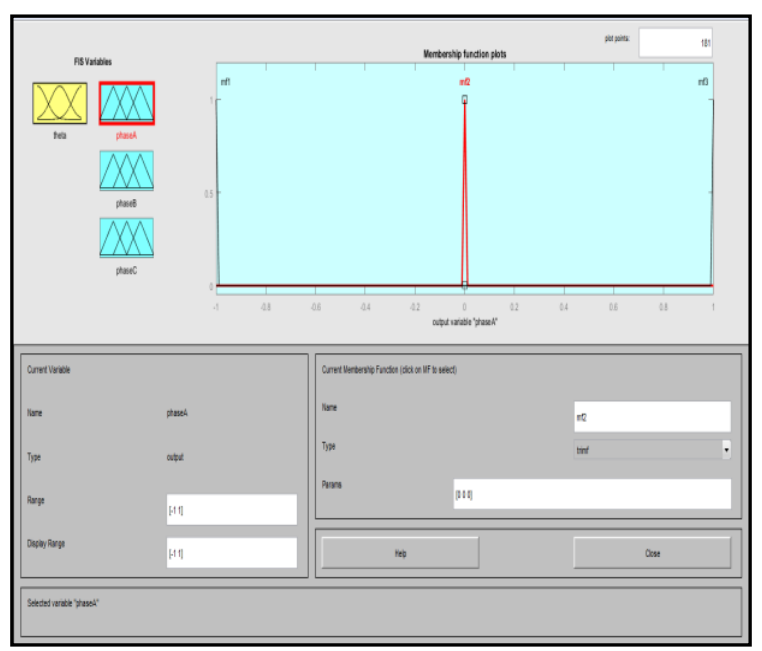

Figure 7.Output Membership Function

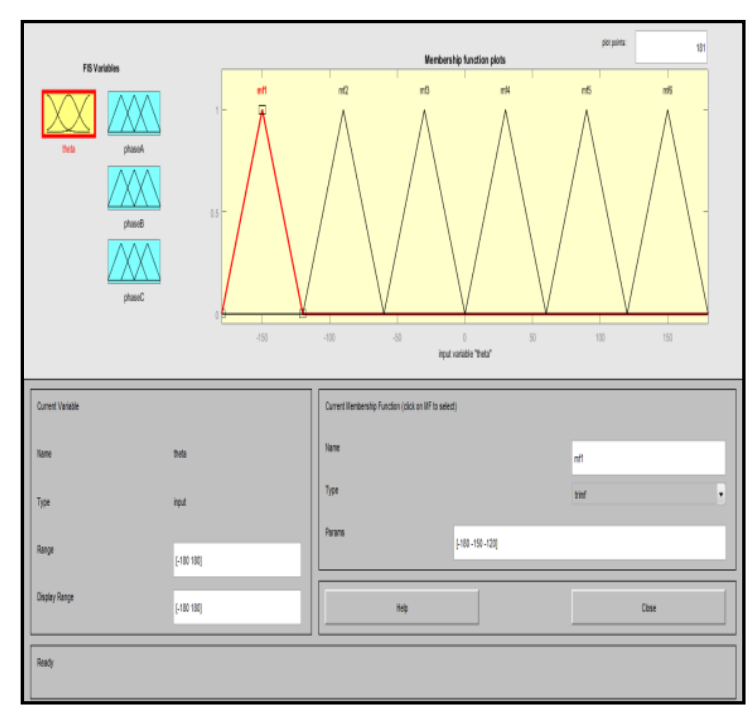

Figure 6. Input Membership Function (Theta)

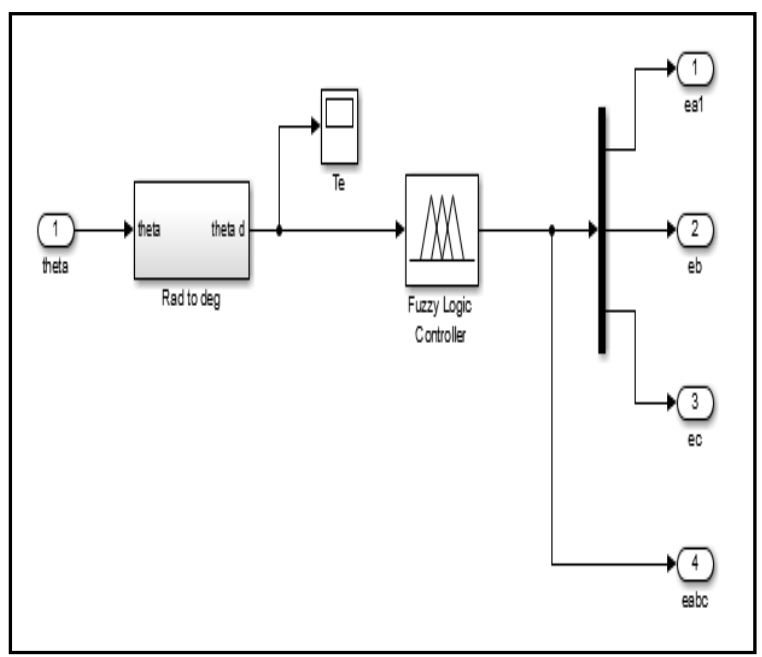

Figure 8. Subsystem-fuzzy Logic Controller 


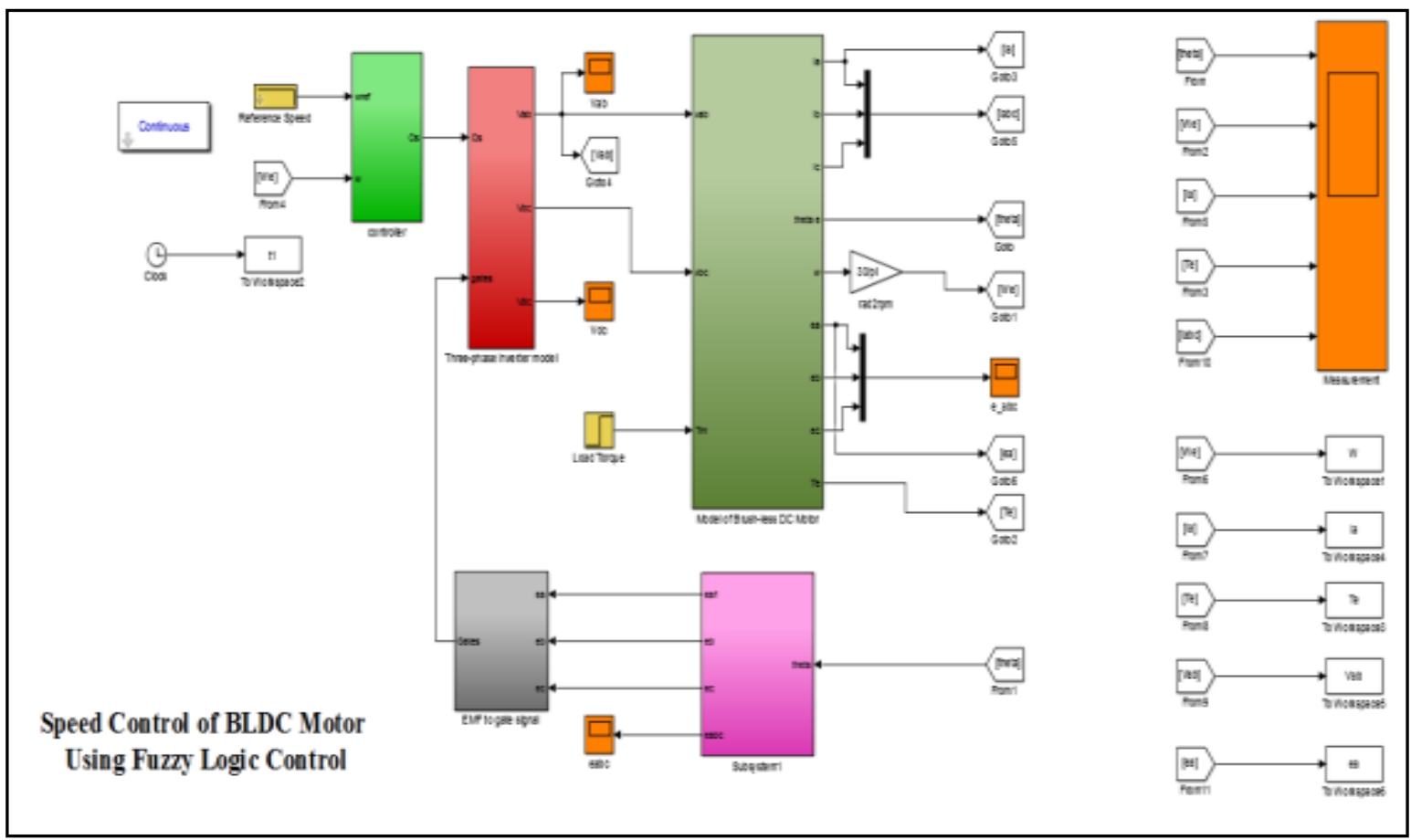

Figure 9. Simulink Model of BLDC Motor Speed Control Using Fuzzy Logic Control

\section{SIMULATION RESULTS}

The simulation is done to compare the performance of BLDC motor when PI and Fuzzy Logic speed controller is used. The BLDC motor Simulink model has been simulated and the waveforms are provided below. BLDC motor reference speed was set at $2000 \mathrm{rpm}$ and then reducing to $1000 \mathrm{r}$.p.m after a time period of 0.4 seconds and applying a load torque of $2 \mathrm{Nm}$ after 0.2 seconds from motor start. Actual motor speed plot in rpm is shown in Figures $14 \& 15$ and the speed reducing to 1000 r.p.m from 2000 rpm gradually and at 0.2 seconds there is a decrease in speed due to load torque and again settling. The motor speed and electromagnetic torque is observed for each case.

\subsection{At No-Load Condition}

Figures $10 \& 11$ show the performance of BLDC motor during no-load condition with PI and Fuzzy Logic speed controller. The motor is set for a reference speed of $2000 \mathrm{rpm}$. From the speed and torque response it is observed that there is smooth change in speed and torque with FLC.

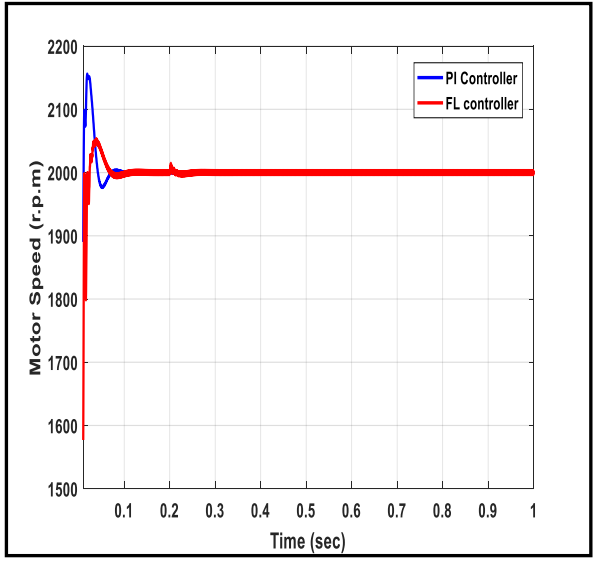

Figure 8. Comparison of Speed Response at no Load Condition

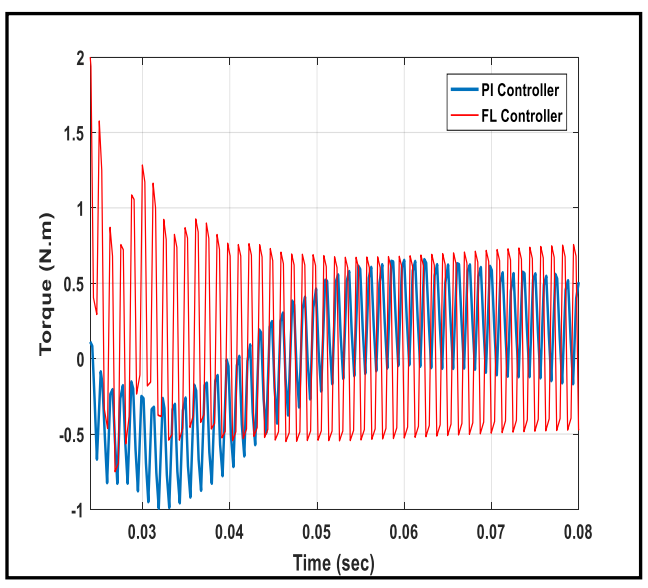

Figure 9. Comparison of Torque Response at no Load Condition 


\subsection{At Constant Load Condition}

Sudden change in load is applied to the motor from no-load to $2 \mathrm{~N}-\mathrm{m}$ at $0.2 \mathrm{sec}$. At this point wave form is distorted for a few second or there is a fluctuation in speed for few second as shown in Figures 12 \& 13. The sudden application of load on motor results in small dip in motor speed. From the torque response it is observed that the torque reduced by PI controller contains ripples at the time of change in load and also at the start while there is a smooth change in torque with change in load when FLC is used.

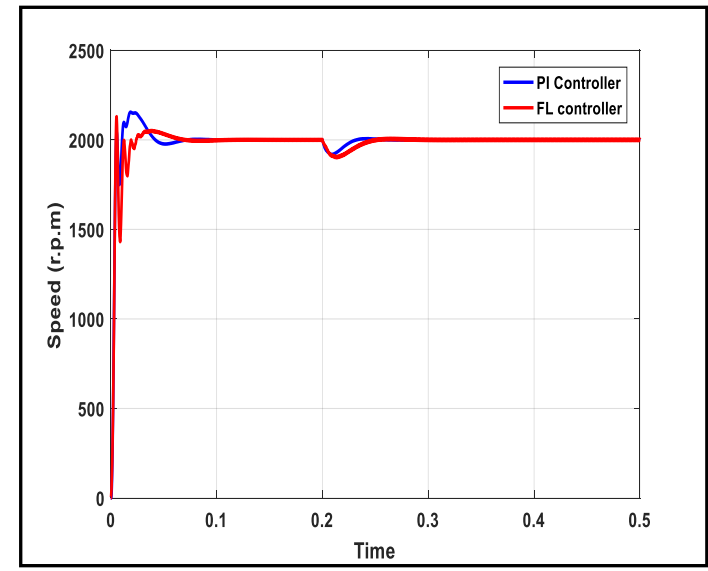

Figure 10. Comparison of Speed Response at Constant Load Condition

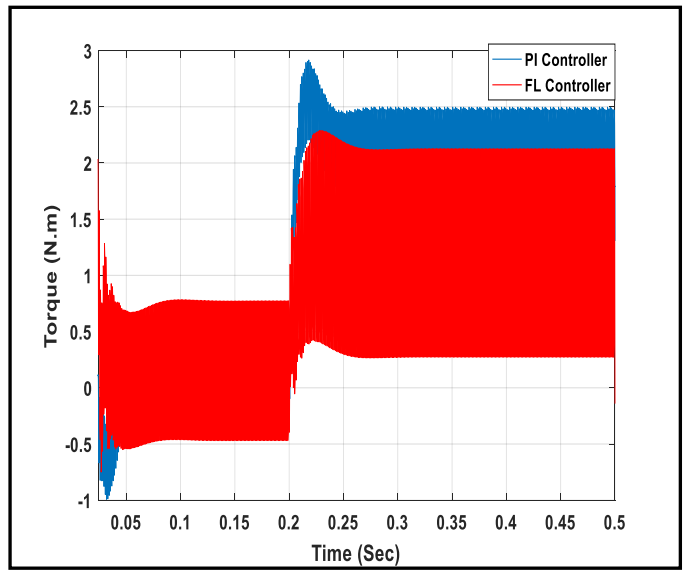

Figure 11. Comparison of Torque Response at Constant Load Condition

\subsection{At Change in Reference Speed Condition}

When there is change in reference speed from $2000 \mathrm{rpm}$ to $1000 \mathrm{rpm}$ at $0.5 \mathrm{sec}$, it is observed that the motor reach the set value with a smooth change in speed with FLC speed controller while the speed contains few ripples before reaching to desired set value when PI controller is used as shown in Figures 14 \& 15. From the torque response it is observed that the toque contains high ripples with PI speed controller as compared to FLC speed controller at the time of change in reference speed.

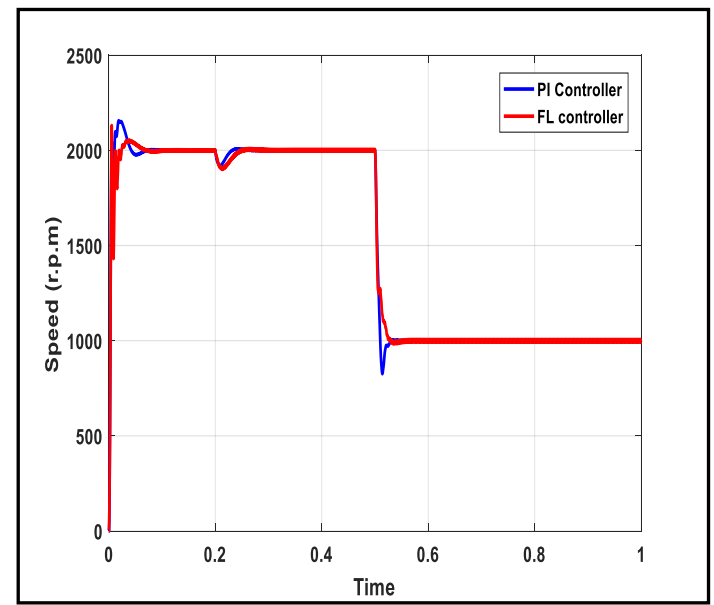

Figure 12.Comparison of Speed Response at Constant Load Condition

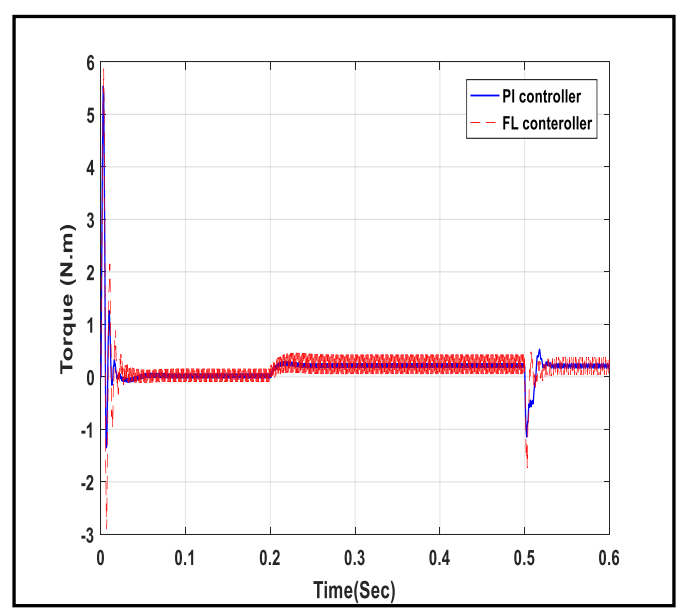

Figure 13. Comparison of Torque Response at Constant Load Condition

\section{CONCLUSION}

This paper is proposed to evaluate the performance of two controllers namely, PI and Fuzzy Logic controllers for speed control of BLDC motor drive system. Fuzzy Logic was used in the design of speed controllers of the drive system and the results are compared with that of PI controller. It has been observed 
that the fuzzy logic controller overcomes the limitations of PI controller like the overshoot in speed, thus the starting current overshoot can be reduced. The advantages of the Fuzzy controller are that it reduces computational time, learns faster and produces lower errors than other method. By proper design a Fuzzy Logic controllers is much better then PI controllers for the speed control of BLDC motor drives.

\section{REFERENCES}

[1] Mohd Syakir Adli, Noor Hazrin Hany Mohamad Hani, Siti Fauziah Toha Tohara. "Brushless DC Motor Speed Controller for Electric Motorbike". International Journal of Power Electronics and Drive System (IJPEDS), June 2018: vol. 9, no. 2, pp. 859 864.

[2] B.-K. Lee, T.-H. Kim, and M. Ehsani. "On The Feasibility Of Four Switch Three-Phase BLDC Motor Drives For Low Cost Commercial Applications: Topology And Control". IEEE Transaction on Power Electronics, 2010: vol. 8, no.1, pp. 164-172.

[3] Krishnan, Pragasan Pillay and R. "Modeling Simulation and Analysis of Permanent Magnet Motor Drives, Part II: The Brushless DC Motor Drives". IEEE Trans. On Industrial Applications, vol. 25, no. 2, pp. 274-279: April 1989.

[4] Zulkifilie Ibrahim and Emil Levi. "A Comparative Analysis Of Fuzzy Logic And Pi Speed Control In High Performance Ac Drives Using Experimental Approach". IEEE Trans. on Industry Applications , 2002: vol. 38, no.5, pp.1210-1218.

[5] Pritha Agrawal, Satya Prakash Dubey, Satyadharma Bharti. "Comparative Study of Fuzzy Logic Based Speed Control of Multilevel Inverter fed Brushless DC Motor Drive". International Journal of Power Electronics and Drive System (IJPEDS), March 2014: vol. 4, no. 1, pp. 70.

[6] Sudhanshu Mitra, Amit Ojha. "Performance Analysis Of BLDC Motor Drive Using PI And Fuzzy Logic Control Scheme ". International Research Journal Of Engineering And Technology (IRJET), Sep-2015.: Volume: 02 no.06.

[7] Anurag SinghTomer, Satya Prakash Dubey. "Response Based Comparative Analysis of Two Inverter Fed Six Phase PMSM Drive by Using PI and Fuzzy Logic Controller." International Journal of Electrical and Computer Engineering (IJECE), December 2016: Vol. 6, no. 6, pp. 2643 265.

[8] Makavana R, Shah BA, Makwana D. "Design of fuzzy logic controller for speed regulation of BLDC motor using MATLAB." International Journal for Scientific Research and Development, 2013: vol. 1, no.2 ,pp. 391-95.

[9] Tan chee Siong, Baharuddin Ismail, Siti Fatimah Siraj, Mohd Faridun Naim Tajuddin, Noor Shahida Jamoshid, Mohd Fayzul Mohammed. "Analysis of Fuzzy Logic Controller for Permanent magnet Brushless Dc Motor Drives." IEEE Student Conference on Research and Development, December 2006: pp. 436-441.

[10] Joon Sung Park, Ki-Doek Lee. "Design and Implementation of BLDC Motor with Integrated Drive Circuit." International Journal of Power Electronics and Drive System (IJPEDS), September 2017: vol. 8, no. 3, pp. $1109 \sim 1116$. 